\title{
Xanthine Oxidase Inhibitory Effect of Solanum torvum (An in Vitro Study)
}

\author{
Yoshita Guntupalli ${ }^{1}$, Kavitha.S'2, V.Vishnupriya ${ }^{3}$ and Gayathri.R ${ }^{4}$ \\ ${ }^{1}$ Saveetha Dental College and Hospitals, Saveetha Institute of Medical and \\ Technical Sciences (SIMATS), Saveetha University, Chennai, India \\ ${ }^{2}$ Lecturer Department of Biochemistry Saveetha Dental college and Hospitals, Saveetha \\ Institute of Medical and Technical Sciences (SIMATS), Saveetha University, Chennai, India \\ ${ }^{3}$ Professor Department of Biochemistry, Saveetha Dental college and Hospitals, Saveetha \\ Institute of Medical and Technical Science (SIMATS), Saveetha University, Chennai, India \\ ${ }^{4}$ Assistant professor. Department of Biochemistry, Saveetha Dental college and Hospitals. Saveetha \\ Institute of Medical and Technical Sciences (SIMATS), Saveetha University, Chennai, India
}

\section{ABSTRACT}

Solanum torvum has been used therapeutically for centuries. Pharmacological studies indicate that the stem and root of S.torvum have anti-tumor, anti-bacterial, anti-viral, anti-inflammatory and other medicinally important effects. It is also used to treat fever, wounds and tooth decay. Gout, a disease resulting from increased uric acid accumulation in joints and muscles and due to increased activities of xanthine oxidase enzyme in nucleotide metabolism. Xanthine oxidase converts xanthine to hypoxanthine and further to uric acid. The present study is focused on evaluating the in vitro xanthine oxidase inhibitory (XOI) activity of $S$. torum fruit extract and to screen the phytochemical constituent present in it. Ethanolic extract of S.torvum (EST) was prepared and xanthine oxidase inhibitory activity was assessed by using Allopurinol as the standard drug. The phytochemical screening of the extract was also done. The results showed that the fruit extract possessed XOI activity in a concentration dependent manner. Also after phytochemical screening showed that EST is rich in phlobatannins, carbohydrates, flavonoids, terpenoids and alkaloids. Thus the study concluded that S.torvum possessed potent in vitro XOI activity.

\section{KEY WORDS: XANTHINE OXIDASE; GOUT; SOLANUM TORVUM; PHYTOCHEMICAL SCREENING.}

\section{INTRODUCTION}

Xanthine Oxidase (X0) is a highly versatile flavoprotein enzyme, ubiquitous among species (from bacteria to human) and within various tissues of mammals (Borges,

\section{ARTICLE INFORMATION}

${ }^{*}$ Corresponding Author: kavithas.sdc@saveetha.com Received 2nd Aug 2020 Accepted after revision 23rd Sep 2020 Print ISSN: 0974-6455 Online ISSN: 2321-4007 CODEN: BBRCBA

Thomson Reuters ISI Web of Science Clarivate Analytics USA and Crossref Indexed Journal

$$
\begin{aligned}
& \text { Clarivate } \\
& \text { Analytics }
\end{aligned}
$$

NAAS Journal Score 2020 (4.31) SJIF: 2020 (7.728)

A Society of Science and Nature Publication,

Bhopal India 2020. All rights reserved.

Online Contents Available at: http//www.bbrc.in/

Doi: $h t t p: / / d x . d o i . o r g / 10.21786 / b b r c / 13.8 / 140$
Fernandes and Roleira, 2002). It is also found in milk. $\mathrm{XO}$ is a homodimer with a molecular mass of $290 \mathrm{kDa}$. It belongs to the molybdenum-protein family containing one molybdenum, one of the flavin adenine dinucleotides (FAD) and two iron sulfur (2Fe-2S) center of Ferredoxin type in each of its two independent subunits. It has two substrate binding sites (Kostis et al., 2015). X0 is a key enzyme playing a role in hyperuricemia, catalyzing the oxidation of hypoxanthine to xanthine and then to uric acid in nucleotide metabolism (Unno, Sugimoto and Kakuda, 2004). Excess or increased activities of X0 leads to excessive production of uric acid which gets accumulated in tissues and results in a diseased condition called Gout and Rheumatoid Arthritis (Sreejith et al., 2013).

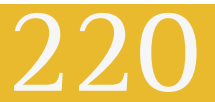


Inhibition of XO decreases uric acid levels and results in an anti-hyperuricemic effect (Borges, Fernandes and Roleira, 2002). Allopurinol, first synthesized as a potential anticancer agent, is nowadays clinically useful as a xanthine oxidase inhibitor used in the treatment of gout. XO serum levels are significantly increased in various pathological stages like hepatitis, inflammation, ischemia-reperfusion, carcinogenesis and ageing (Borges, Fernandes and Roleira, 2002). However, Allopurinol being a chemical has many side effects such as fever, sore throat and allergic reactions. There have been many studies conducted for discovering various xanthine oxidase inhibitors which could be used in treatment of gout and related diseases without any side effects.

Numerous studies have been conducted regarding the XOI activity of plants and plant products. Flacourtia sepiaria was traditionally used as an antidote for snake poisoning, rheumatoid arthritis, gout and kidney diseases. The XOI activity of its methanol extract was found to be significant when compared with standard Allopurinol (Sreejith et al., 2013). Phenolic substances like anthocyanins and polyphenols present in berries of several cultivars of Ribes, Rubus and vaccinium genera had certain inhibitory activity towards XO (Costantino, Albasini and Rastelli, 1992). Erythrina stricta, an evergreen tree, is very effective in treatment of gout due to its XOI activity (Umamaheswari et al., 2009). Ursolic acid also has good hypouricemic activity and therefore has high potential to be used for treatment of gout and hyperuricemia related diseases (Abu-Gharbieh et al., 2018).

S.torvum is a small solanaceous shrub. The plant is found in tropical Africa, Asia, South America. Anciently, it was used in Cameroonian folk medicine for treatment of fever, wounds and tooth decay (Ndebia, Kamgang and Nkeh-ChungagAnye, 2006). The other names of S.torvum include devil's fig, prickly nightshade, shooshoo bush, wild eggplant and pea eggplant. It is bushy, spiny and erect. The berries grow in clusters of tiny green spheres which resemble green peas when ripe and later become yellow to brown (Ve et al., 2018). Its taxonomic classification is as follows (Jaiswal, 2012):

Kingdom: Plantae

Division: Magnoliophyta

Class : Magnoliopsida

Order : Solanales

Family : Solanaceae

Genus : Solanum L.

Species : torvum

Among its major chemical constituents are steroids, steroid saponins, steroid alkaloids and phenols (Yousaf, Wang and Baydoun, 2013). It is used in the treatment of coughs and liver diseases. Solanum torvum is used to reduce body heat and strengthen the body. It has good antibacterial activity (Kannan et al., 2012). Many pharmacological studies revealed that this plant exhibits antioxidant activity, cardiovascular, immunomodulatory and nephroprotective activity supporting its traditional uses (Jaiswal, 2012). Aqueous extract from dried fruits of Solanum torvum reduces blood pressure. It also has antiulcer properties owing to presence of flavonoids, sterols and triterpenes. It is antiviral, analgesic as well as antiinflammatory (Agrawal, Bajpei and Patil, 2010). Hence our present study is to assess the inhibitory activity of $S$. torvum on xanthine oxidase in an in vitro model.

\section{MATERIAL AND METHODS}

2.1 S.torvum fruit extract (EST) preparation: Ethanolic extract of S.torvum was prepared. The fruits were collected, washed and dried thoroughly. Then 30 grams of fruit was weighed out and ground with ethanol. This mixture was kept for one day and then filtered. The extract thus prepared (EST) was dried and used for assessing the XOI activity.

2.2 In vitro XOI activity of S. torvum fruit extract: In vitro XOI activity of EST was assessed as per the method of (Nguyen et al., 2004) and (Umamaheswari et al., 2007) . Briefly, the assay mixture consisted of $1 \mathrm{ml}$ of the EST (0.1 to $0.5 \mathrm{~g} / \mathrm{ml}$ ), $2.9 \mathrm{ml}$ of phosphate buffer ( $\mathrm{pH} 7.5$ ) and $0.1 \mathrm{ml}$ of xanthine oxidase enzyme solution (0.1 units) $\mathrm{ml}$ in Phosphate buffer, $\mathrm{pH}$ 7.5), which was prepared immediately before use. After preincubation at $25^{\circ}$ for 15 $\mathrm{min}$, the reaction was initiated by the addition of $2 \mathrm{ml}$ of substrate solution (150 M xanthine in the same buffer). The assay mixture was incubated at $25^{\circ}$ for $30 \mathrm{~min}$. The reaction was then stopped by the addition of $1 \mathrm{ml}$ of $1 \mathrm{~N}$ hydrochloric acid and the absorbance was measured at $290 \mathrm{~nm}$ using a UV spectrophotometer. Allopurinol (0.1 to $0.5 \mathrm{mg} / \mathrm{ml}$ ), a known inhibitor of $\mathrm{XO}$, was used as the positive control. One unit of XO is defined as the amount of enzyme required to produce $1 \mathrm{mmol}$ of uric acid/min at $25^{\circ}$. XOI activity was expressed as the percentage inhibition of XO in the above assay system calculated as percentage of inhibition as follows

$$
\% \text { of inhibition }=[(\mathrm{Ac}-\mathrm{At}) / \mathrm{Ac}] \times 100
$$

Where Ac is the absorbance of control reaction and At is the absorbance of test reaction. The assay was done in triplicate for each concentration. Allopurinol (0.1 to $0.5 \mu \mathrm{g} / \mathrm{ml}$ ) was used as standard.

\subsection{Phytochemical Screening test}

2.3.1. Test for phlobatannin: $1 \mathrm{ml}$ of the EST was treated with $1 \mathrm{ml}$ of $1 \% \mathrm{HCl}$ and boiled for 10 mins. The formation of red color precipitate indicates the presence of phlobatannin.

\subsubsection{Test for Carbohydrates}

a) Fehling's test: $1 \mathrm{ml}$ of the extract was boiled with $1 \mathrm{ml}$ of Fehling's A and B for 3min. The formation of brown or red precipitate indicating the presence of carbohydrates (reducing sugar).

b) Benedict's test: $1 \mathrm{ml}$ of the extract was boiled along with $1 \mathrm{ml}$ of Benedict's solution. Red, brown or green color precipitate indicates the presence of carbohydrates (reducing sugar). 
2.3.3. Test for Flavonoids: Few drops of 1\% liquid ammonia were taken in a test tube and along with it. $1 \mathrm{ml}$ of the extract was added. The formation of yellow color indicates the presence of flavonoids.

2.3.4. Test for Alkaloids: $2 \mathrm{ml}$ of extract was mixed with $2 \mathrm{ml}$ of $\mathrm{HCl}$. Then 6 drops of HCN was added and further 2 drops of picric acid was added. The formation of a creamish pale yellow precipitate indicates the presence of Alkaloids.

2.3.5. Test for Terpenoids: $2 \mathrm{ml}$ of extract along with $2 \mathrm{ml}$ of chloroform and $3 \mathrm{ml}$ of con. H2SO4 was added. The formation of red precipitate indicates the presence of terpenoids.

Figure 1: Xanthine oxidase inhibitory activity of Solanum torvum. Allopurinol: Was used as a standard drug. Each Bar Represents Mean \pm SEM of 3 independent observations. $\mathrm{p}<0.05$ is considered to be statistically significant.

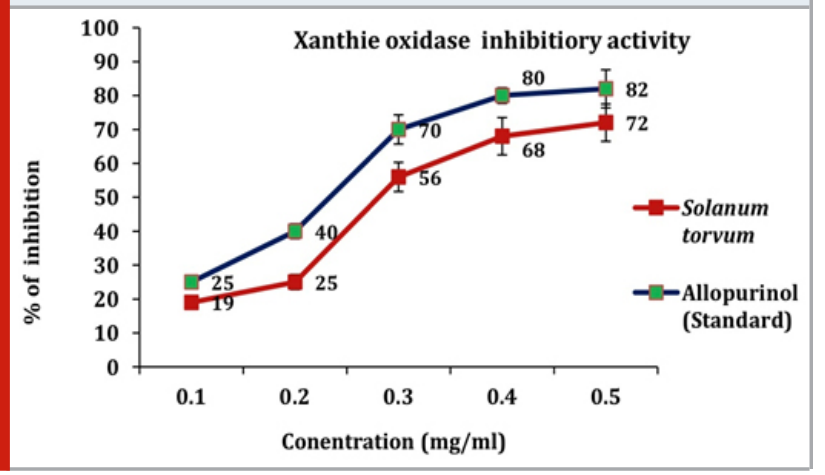

2.4 Statistical Analysis: The data was subjected to statistical analysis using one-way analysis of variance (ANOVA) and Duncan's multiple range test to assess the significance of individual variations between the groups. In Duncan's test, significance was considered at the level of $\mathrm{p}<0.05$.

\section{RESULTS AND DISCUSSION}

Natural products provide a vast pool of XO inhibitors that can possibly be developed into clinical products. At present, the potential of developing successful natural products for the management of XO-related diseases is still largely unexplored (Hudaib et al., 2011). Uricosuric drugs which increase the urinary excretion of uric acid, or XO inhibitors which block the terminal step in uric acid biosynthesis, can lower the plasma uric acid concentration, and are generally employed for the treatment of gout (Schlesinger, Dalbeth and PerezRuiz, 2009). S.torvum fruit extract was found to have significant XOI activity in a concentration dependent manner (Figure 1). With increasing concentration of EST, the percentage inhibition of xanthine oxidase was also increased, showing its efficacy in a concentration dependent manner. When its XOI activity was compared to that of standard, Allopurinol, the activity was found to be slightly lesser. However, allopurinol causes many side effects such as hepatitis, nephropathy, and allergic reactions (Fagugli et al., 2008). The graph (Figure 1) shows that the activity of allopurinol is high when compared to that of the extract. The XOI activity of the extract could decrease the accumulation of uric acid and its deposition which is the key process in the development of gout.

\begin{tabular}{|c|c|c|c|}
\hline Experiment & Observation & Result & Inference \\
\hline Test for Phlobatannins: & $\begin{array}{l}\text { Red colored complex } \\
\text { formed }\end{array}$ & +++ & Presence of Phlobatannins \\
\hline Fehling's Test: & $\begin{array}{l}\text { Reddish brown color } \\
\text { formed }\end{array}$ & +++ & Presence of Carbohydrates \\
\hline Benedict's Test: & $\begin{array}{l}\text { Red, brown or green } \\
\text { color formed }\end{array}$ & +++ & Presence of Carbohydrates \\
\hline Test for Flavonoids: & $\begin{array}{l}\text { Creamish yellow } \\
\text { color formed }\end{array}$ & ++ & Presence of Flavonoids \\
\hline Test for Alkaloids: & Red color formed & +++ & Presence of Alkaloids \\
\hline Test for Terpenoids: & Red color formed & +++ & Presence of Terpenoids \\
\hline
\end{tabular}

Phytochemicals are a powerful group of compounds, belonging to secondary metabolites of plants and including a diverse range of chemical entities such as polyphenols, flavonoids, steroidal saponins, organosulfur compounds, and vitamins (Forni et al., 2019). Most phytochemicals, components of food, beverages, and herbal products are often reported in literature as "nutraceutical", emphasizing their health promoting properties, including the prevention and treatment of pathologies like cancer, cardiovascular diseases, neural disorders, and Alzheimer's disease (Winter et al., 2017). The phytochemical analysis of EST showed that the extract is found to be rich in phlobatannins, carbohydrates, alkaloids, terpenoids and flavonoids, which attribute to its biochemical activities and properties. These secondary metabolites have been documented to possess an array of pharmacological properties attributable to their ability to interfere with multiple signalling cascades that are critical to heterogeneous metabolic diseases (Ramawat, Dass and Mathur, 2009; Forni et al., 2019). The occurrence of these 
phytochemicals might have contributed to the beneficial effects of this extract.

\section{CONCLUSION}

To conclude the extract showed potent XOI activity and is rich in many phytochemicals. This study provides a platform for the further analysis of the extract in detail about the antigout activity. Detailed in vivo studies are needed for development of this plant fruit as a drug for the treatment of gout.

\section{ACKNOWLEDGEMENTS}

This research was done under the supervision of the Department of Research of Saveetha Dental College and Hospitals. We sincerely show gratitude to the corresponding guides who provided insight and expertise that greatly assisted the research.

Conflicts of Interest: None declared

\section{REFERENCES}

Abu-Gharbieh, E. et al. (2018) 'Antihyperuricemic and xanthine oxidase inhibitory activities of Tribulus arabicus and its isolated compound, ursolic acid: In vitro and in vivo investigation and docking simulations', PloS one. journals.plos.org, 13(8), p. e0202572.

Agrawal, A. D., Bajpei, P. S. and Patil, A. A. (2010) 'Solanum torvum Sw.-a phytopharmacological review', Der pharmacia. researchgate.net. Available at: https:// www.researchgate.net/file.PostFileLoader.html?id=54a 69921d11b8b2a478b45e5ctassetKey=AS\%3A2736615 $36210947 \% 401442257402819$.

Borges, F., Fernandes, E. and Roleira, F. (2002) 'Progress towards the discovery of xanthine oxidase inhibitors', Current medicinal chemistry. ingentaconnect.com, 9(2), pp. 195-217.

Costantino, L., Albasini, A. and Rastelli, G. (1992) 'Activity of polyphenolic crude extracts as scavangers of superoxide radicals and inhibitors of Xanthine Oxidase', Planta medica. thieme-connect.com. Available at: https://www.thieme-connect.com/products/ejournals/ abstract/10.1055/s-2006-961481.

Fagugli, R. M. et al. (2008) 'Acute renal and hepatic failure associated with allopurinol treatment', Clinical nephrology. researchgate.net, 70(6), pp. 523-526.

Forni, C. et al. (2019) 'Beneficial Role of Phytochemicals on Oxidative Stress and Age-Related Diseases', BioMed research international. hindawi.com, 2019, p. 8748253.

Hudaib, M. M. et al. (2011) 'Xanthine oxidase inhibitory activity of the methanolic extracts of selected Jordanian medicinal plants', Pharmacognosy magazine. ncbi.nlm. nih.gov, 7(28), pp. 320-324.

Jaiswal, B. S. (2012) 'Solanum torvum: A review of its traditional uses, phytochemistry and pharmacology'. Available at: https://www.semanticscholar.org/ paper/c22566822ce0dd68bfd1190ffeb7f9ff6744b4f4 (Accessed: 29 June 2020).
Kannan, M. et al. (2012) 'Phytochemical, antibacterial and antioxidant studies on medicinal plant Solanum torvum', Journal of pharmacy research, 5(5), pp. 2418-2421.

Kostis, D. A. et al. (2015) 'Xanthine Oxidase: Isolation, Assays of Activity, and Inhibition', Journal of chemistry and chemical engineering. Hindawi, 2015. doi: $10.1155 / 2015 / 294858$.

Ndebia, E. J., Kamgang, R. and Nkeh-ChungagAnye, B. N. (2006) 'Analgesic and anti-inflammatory properties of aqueous extract from leaves of Solanum torvum (Solanaceae)', African journal of traditional, complementary, and alternative medicines: AJTCAM / African Networks on Ethnomedicines. ajol.info, 4(2), pp. 240-244.

Nguyen, M. T. T. et al. (2004) 'Xanthine oxidase inhibitory activity of Vietnamese medicinal plants', Biological \& pharmaceutical bulletin. jstage.jst.go.jp, 27(9), pp. 1414-1421.

Ramawat, K. G., Dass, S. and Mathur, M. (2009) 'The Chemical Diversity of Bioactive Molecules and Therapeutic Potential of Medicinal Plants', in Ramawat, K. G. (ed.) Herbal Drugs: Ethnomedicine to Modern Medicine. Berlin, Heidelberg: Springer Berlin Heidelberg, pp. 7-32.

Schlesinger, N., Dalbeth, N. and Perez-Ruiz, F. (2009) 'Gout--what are the treatment options?', Expert opinion on pharmacotherapy. Taylor \& Francis, 10(8), pp. 1319-1328.

Sreejith, M. et al. (2013) 'In vitro xanthine oxidase inhibitory and antioxidant activities of aerial parts of Flacourtia sepiaria Roxb', Oriental pharmacy and experimental medicine. Springer, 13(2), pp. 113-120. Umamaheswari, M. et al. (2007) 'Xanthine oxidase inhibitory activity of some Indian medical plants', Journal of ethnopharmacology. Elsevier, 109(3), pp. 547-551.

Umamaheswari, M. et al. (2009) 'In vitro xanthine oxidase inhibitory activity of the fractions of Erythrina stricta Roxb', Journal of ethnopharmacology. Elsevier, 124(3), pp. 646-648.

Unno, T., Sugimoto, A. and Kakuda, T. (2004) 'Xanthine oxidase inhibitors from the leaves of Lagerstroemia speciosa (L.) Pers', Journal of ethnopharmacology. Elsevier, 93(2-3), pp. 391-395.

Ve, I. C. et al. (2018) 'Phytochemicals detection, antioxidant and antimicrobial activity study on berries of Solanum torvum', Asian Journal of Pharmaceutical and Clinical Research. Innovare Academic Sciences Pvt Ltd, 11(11), pp. 418-423.

Winter, A. N. et al. (2017) 'Comparison of the Neuroprotective and Anti-Inflammatory Effects of the Anthocyanin Metabolites, Protocatechuic Acid and 4-Hydroxybenzoic Acid', Oxidative medicine and cellular longevity. hindawi.com, 2017, p. 6297080.

Yousaf, Z., Wang, Y. and Baydoun, E. (2013) 'Phytochemistry and pharmacological studies on Solanum torvum Swartz', Journal of Basic and Applied Pharmaceutical Sciences. japsonline.com, 3(4), pp. 152-160. 